
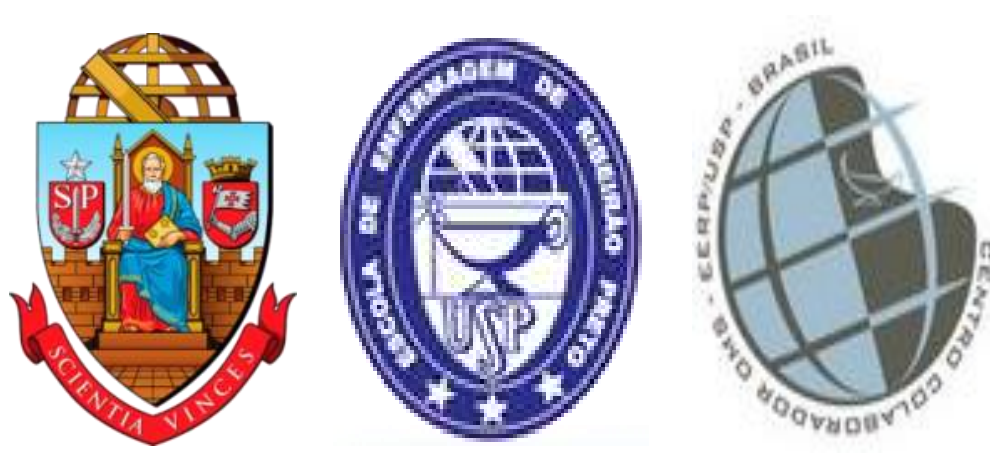

University of Sao Paulo

Faculty of Nursing at Ribeirão Preto

Department of Psychiatric Nursing

\title{
Child maltreatment, psychological, mental problems and substance use experienced by adolescents in conflict with the law: sons of substance users
}

L.G. Perruci' ${ }^{\text {, A. Diehl }}{ }^{2}$, B.V. Silveira ${ }^{1}$, R. Souza Molina de ${ }^{3}$, J.D. Souza ${ }^{1}$, C. Wagstaff ${ }^{4}$, S.C. Pillon ${ }^{1}$.

${ }^{1}$ Faculty of Nursing at Ribeirão Preto, Psychiatric Nursing and Human Science, Ribeirão Preto, Brazil.

${ }^{2}$ Federal University of São Paulo, Psychiatric, São Paulo, Brazil.

${ }^{3}$ Federal Technological University of Paraná. Academic Department of Mathematics DAMAT, Cornélio Procópio, Brazil.

${ }^{4}$ Institute of Clinical Sciences. University of Birmingham- Medical School, Nursing, Birmingham, United Kingdom.

\section{BACKGROUND}

Several studies highlight the role of the family as a protective factor or risk for psychoactive substance use by teenagers. Parents and dysfunctional families, related to family conflicts, emotional neglect and care, drug use by parents, violent practices and experiences, among others, interfere in the confrontation of problems for adolescents, in social skills, as well as in decision making by them.

\section{OBJECTIVE}

To evaluate the associations between having parents with drug-related problems and having suffered neglect in family care and emotional and behavioral problems (psychological and drug use) experienced by adolescents in assisted freedom in compliance with

\section{MATERIALS AND METHODS}

A cross-sectional study with 150 adolescents (12 to 17 years old) who fulfilled socio educational measures in assisted care. The Drug Abuse Screening Test, Teen Addiction Severity Index and Childhood Trauma Questionnaire were used.

\section{RESULTS AND CONCLUSIONS}

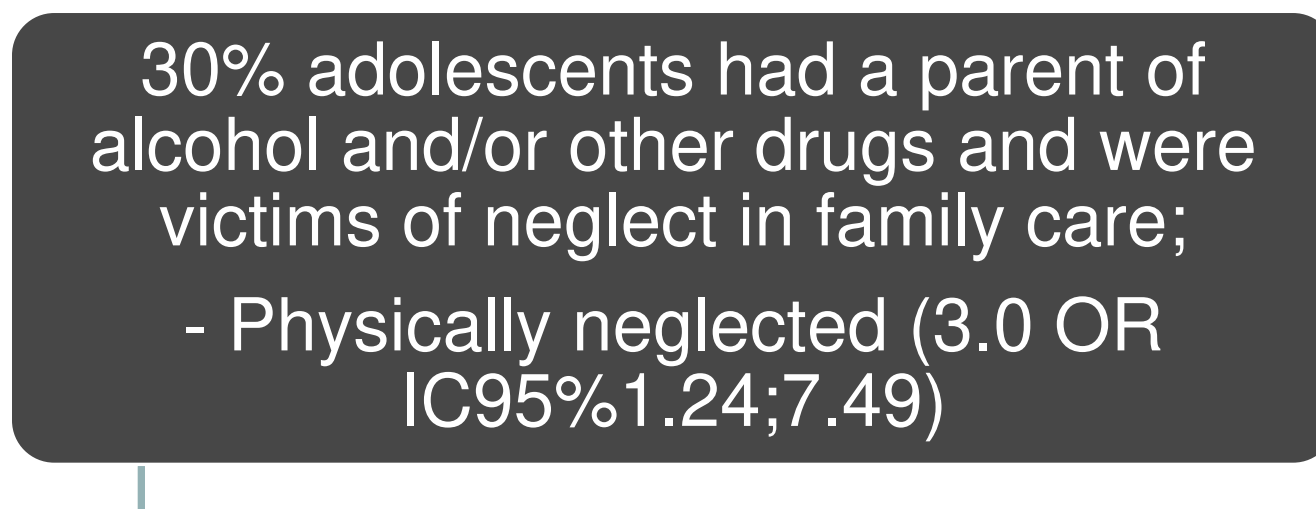

$22 \%$ - criteria for disorders such as severe depression and problems in controlling violent behavior (ORA2.6 95\%CI $1.12 ; 5.87)$

$51 \%$ anxiety and $46 \%$ difficulties in comprehension, concentration or memory, whereas $24.6 \%$ showed signs of hallucinations (ORA2.8 95\%Cl 1.25;6.14)

Dysfunctional behavior (substance use and family neglect) by parents and child abuse were strongly associated. The findings of the study have implications for the implementation of inter-sectoral actions integrated between social assistance, health and justice.

Descriptors: Adolescent. Child Abuse. Child Maltreatment. Substance-Related Disorders. Parenting. Juvenile Delinquency. 